\title{
ADIÇÃO DE FITASE EM RAÇÕES COM DIFERENTES NÍVEIS DE ENERGIA METABOLIZÁVEL, PROTEÍNA BRUTA E FÓSFORO DISPONÍVEL PARA FRANGOS DE CORTE DE 1 A 21 DIAS
}

\author{
Renata Ribeiro Alvarenga ${ }^{1}$, Adriano Kaneo Nagata ${ }^{2}$, Paulo Borges Rodrigues ${ }^{3}$, Márcio \\ Gilberto Zangeronimo ${ }^{3}$, Luis EdUardo Avelar PuCCI ${ }^{4}$, Renato HesPanhol ${ }^{5}$ \\ ${ }^{1}$ Pós-Graduanda da Universidade Federal de Lavras, Lavras, MG.- renatazoote@ yahoo.com.br \\ ${ }^{2}$ Assistente Técnico Doutor da Tortuga Cia. Zootécnica Agrária, São Paulo, SP. \\ ${ }^{3}$ Professores Doutores da Universidade Federal de Lavras, Lavras, MG \\ ${ }^{4}$ Pós-doutorando em Zootecnia da Universidade Federal de Lavras, MG. \\ ${ }^{5}$ Zootecnista pela Universidade Federal de Lavras, Lavras, MG.
}

Objetivou-se avaliar o desempenho e a excreção de poluentes em frangos de corte de 1 a 21 dias recebendo dietas com fitase combinada com diferentes níveis de energia metabolizável (EMAn), proteína bruta (PB) e fósforo disponível (Pd) e suplementadas com aminoácidos. Para a avaliação do desempenho, 1.350 pintos machos Cobb com um dia de idade (peso de 45,5 \pm $0,9 \mathrm{~g}$ ) foram distribuídos em delineamento inteiramente casualizado em esquema fatorial $4 \times 2+1$ (quatro níveis de EMAn - 2850, 2950, 3050 e $3150 \mathrm{kcal} / \mathrm{kg}$ - e dois de PB com fósforo disponível - 17 com $0,34 \%$ e 19 com $0,26 \%$, respectivamente, todos com fitase - e um tratamento adicional - controle, sem fitase, com $21 \%$ PB, 3000 $\mathrm{kcal} / \mathrm{kg}$ de EMAn e 0,46\% de Pd), em seis repetições de 25 aves cada. Para a avaliação da excreção de poluentes, foram utilizados 270 pintos aos 14 dias de idade alojados em gaiolas metabólicas em grupos de cinco, durante sete dias, utilizando-se o mesmo delineamento. O uso de fitase, apesar de reduzir a excreção de fósforo e de cobre, piorou o ganho de peso e a conversão alimentar, em todos os planos nutricionais estudados. Em rações com fitase, os níveis energéticos reduziram de forma linear o consumo de ração e melhoraram a conversão alimentar e a excreção de cálcio e potássio. A energia reduziu a excreção de nitrogênio, fósforo e zinco somente em rações com $17 \%$ $\mathrm{PB}$ e $0,34 \%$ de $\mathrm{Pd}$. A redução da $\mathrm{PB}$ em rações com fitase melhorou a conversão alimentar, além de reduzir a excreção de nitrogênio e potássio. Conclui-se que a fitase piora o desempenho de frangos de corte até a terceira semana de idade quando combinada com níveis reduzidos de PB e Pd.

PALAVRAS-CHAVE: aditivo; enzimas; nutrição; qualidade das excretas; proteína ideal.

\section{PHYTASE ADDITION TO DIETS WITH DIFFERENT LEVELS OF METABOLIZABLE ENERGY, CRUDE PROTEIN AND AVAILABLE PHOSPHORUS TO BROILERS FROM 1 TO 21 DAYS OF AGE}

The objective of this study was to evaluate the performance and the pollutant excretion of broilers from 1 to 21 days of age fed diets with different levels of metabolizable energy (MEn), crude protein (CP) and available phosphorus (aP), supplemented with amino acids and phytase. To evaluate the performance, 1,350 Cobb broilers at one day of age (weight of $45.5 \pm 0.9 \mathrm{~g}$ ) were distributed in a completely randomized design in a $4 \times 2+1$ factorial arrangement (four levels of MEn - 2,850; 2,950;
3,050 and $3,150 \mathrm{kcal} / \mathrm{kg}$ - and two of $\mathrm{CP}$ and aP - 17 with $0.34 \%$ and 19 with $0.25 \%$, respectively, all with phytase, and an additional treatment - control, without phytase, with $21 \% \mathrm{~PB}, 3,000 \mathrm{kcal} / \mathrm{kg} \mathrm{MEn}$ and $0.46 \% \mathrm{aP}$ ), in six replications with 25 birds. To evaluate the excretion of pollutants, 270 broilers at 14 days of age were allotted in metabolic cages in groups of five during seven days, using the same statistical design. Although the use of phytase reduced phosphorus and copper excretion, it decreased 
weight gain and increased feed conversion ratio in all studied nutritional plans. In phytase-diets, the energetic levels linearly reduced feed intake and improved feed conversion ratio and calcium and potassium excretion. Energy reduced the nitrogen, phosphorus and zinc excretion only in $17 \% \mathrm{CP}$ and $0.34 \%$ aP diets. Crude protein reduction in phytase-diets improved feed conversion ratio and reduced nitrogen and potassium excretion. It was concluded that phytase decreases broiler performance until the third week of age when combined with reduced levels of $\mathrm{CP}$ and aP in diets.

KEYWORDS: additive; enzyme; excrement quality; ideal protein; nutrition.

\section{INTRODUÇÃO}

A velocidade de expansão da avicultura vem acompanhada da assimilação contínua de moderna tecnologia, colocando o Brasil no grupo dos três maiores produtores mundiais de carne de frango. Nesse contexto, o uso de dietas para maximizar o desempenho e ainda diminuir o impacto ambiental causado pelos resíduos tem sido alvo de pesquisas nos últimos anos. Desta forma, a máxima eficiência no aproveitamento dos nutrientes da dieta e a redução da excreção desses nutrientes para o meio ambiente são atributos essenciais aos modernos sistemas de produção.

A utilização da cama de frango na alimentação animal e o uso como fertilizantes vem sofrendo restrições, primeiro devido ao aparecimento da encefalopatia espongiforme bovina e, segundo, quando aplicado ao solo sem critérios agronômicos, torna-se prejudicial para plantas, lençóis freáticos e organismos aquáticos. Assim, faz-se necessário realizar pesquisas por meio da manipulação de dietas para tentar amenizar problemas relacionados ao ambiente.

Atualmente, diversos aditivos têm sido utilizados em rações no intuito de melhorar o aproveitamento de nutrientes pelos animais, dentre os quais a fitase, que tem comprovado efeito no aproveitamento do fósforo fítico dos alimentos (SILVA et al., 2008). No entanto, existem relatos de que essa enzima também pode disponibilizar carboidratos, aminoácidos e íons, como fosfato, cálcio, potássio, zinco e cobre (SILVA et al., 2006), podendo, nesse caso, alterar o balanço energético, eletrolítico e de aminoácidos. Isto se torna mais importante ao se utilizar rações formuladas seguindo o conceito de proteína ideal, a qual está associada à redução do farelo de soja e inclusão de aminoácidos cristalinos.

Assim, objetivou-se avaliar o fornecimento de dietas com níveis reduzidos de proteína bruta e fósforo disponível, formuladas com diferentes níveis de energia metabolizável aparente corrigida (EMAn), suplementadas com aminoácidos e fitase, sobre o desempenho e excreção de poluentes por frangos de corte de um a 21 dias de idade.

\section{MATERIAL E MÉTODOS}

O experimento foi conduzido no Setor de Avicultura do Departamento de Zootecnia (DZO) da Universidade Federal de Lavras (UFLA), em Lavras, MG.

Para o desempenho, foram utilizados 1.350 pintos machos da linhagem Cobb com um dia de idade e peso inicial de 45,5 $\pm 0,9 \mathrm{~g}$, distribuídos aleatoriamente em galpão de alvenaria em 54 boxes com piso forrado com maravalha, todos com comedouro tubular e um bebedouro pendular. Água e ração foram fornecidas à vontade. $\mathrm{O}$ período experimental foi de 20 dias.

Paralelamente, foi conduzido um ensaio de metabolismo no qual foram utilizados 270 pintos da mesma linhagem aos 14 dias de idade, distribuídos em baterias metálicas $(50 \times 50 \times 50 \mathrm{~cm})$ providas de bebedouro tipo "copo de pressão" e comedouro tipo calha com bordas de madeira para evitar desperdício, além de bandejas coletoras de excretas, colocadas em sala de metabolismo com ambiente controlado, recebendo luz artificial por 24 horas. Água e ração foram fornecidas à vontade, durante um período experimental de sete dias.

Em ambos os ensaios, foi utilizado um delineamento experimental inteiramente casualizado em esquema fatorial $4 \times 2+1$ (quatro níveis de energia metabolizável aparente corrigida - 2850, 2950, 3050 e $3150 \mathrm{kcal} / \mathrm{kg}$ - e dois de proteína bruta e fósforo disponível - 17 e $0,34 \%$ e 19 e $0,26 \%$, respectivamente - e um tratamento adicional), totalizando nove tratamentos com seis repetições de 25 aves cada para o ensaio de desempenho e cinco aves para o ensaio de metabolismo. O tratamento adicional foi constituído por uma ração controle, formulada de acordo com os níveis nutricionais recomendados por ROSTAGNO et al. (2000). Nas rações contendo fósforo reduzido $(0,24$ e $0,36 \%)$, foram adicionados $500 \mathrm{FTU}$ de fitase/kg (Ronozyme $-2500 \mathrm{FTU} / \mathrm{g}$ ). Os níveis de cálcio foram fixados em $0,8 \%$ (Schoulten et al., 2003). As rações foram formuladas com milho e farelo de soja, mantendo-se a relação ideal dos aminoácidos com a lisina seguindo o conceito de proteína ideal (Tabela 1).

No ensaio de metabolismo foi utilizado o método tradicional de coleta total de excretas, 
descrito por MATTERSON et al. (1965). As aves passaram por um período de quatro dias de adaptação às gaiolas, quando então se iniciou o período de três dias de coleta total diária de excretas (RODRIGUES et al., 2005). Durante esse período, as excretas foram coletadas em bandejas revestidas com plástico e separadas das penas. As sobras de ração foram recolhidas e congeladas até o final do período experimental, quando foram tomadas amostras juntamente com as rações e as excretas para mensuração das análises bromatológicas, segundo metodologia descrita por SILVA \& QUEIROZ (2002).

Foram determinados a energia bruta, o nitrogênio, o fósforo, o cálcio, o potássio, o zinco e o cobre nas rações e nas excretas. Para os cálculos dos valores de EMAn das rações, foram utilizadas as equações descritas por MATTERSON et al. (1965) e, para os coeficientes de retenção aparente do nitrogênio, fósforo, cálcio, potássio, zinco e cobre, a seguinte fórmula:

$$
\text { coeficiente de retenção }=\frac{\text { g de nutriente ingerido-g de nutriente excretado }}{\text { g de nutriente ingerido }} \times 100
$$

Tabela 1 - Composição centesimal das rações experimentais ${ }^{1}$

\begin{tabular}{|c|c|c|c|c|c|c|c|c|c|}
\hline \multirow{3}{*}{ Ingrediente } & \multirow{3}{*}{ Dieta controle } & \multicolumn{4}{|c|}{$17 \%$ PB e $0,34 \%$ Pd } & \multicolumn{4}{|c|}{$19 \% \mathrm{~PB}$ e $0,26 \% \mathrm{Pd}$} \\
\hline & & \multicolumn{4}{|c|}{ EMAn $(\mathrm{kcal} / \mathrm{kg})^{1}$} & \multicolumn{4}{|c|}{ EMAn $(\mathrm{kcal} / \mathrm{kg})^{1}$} \\
\hline & & 2850 & 2950 & 3050 & 3150 & 2850 & 2950 & 3050 & 3150 \\
\hline Milho & 56,60 & 66,30 & 66,30 & 66,30 & 66,30 & 61,20 & 61,20 & 61,20 & 61,20 \\
\hline Farelo de Soja & 35,70 & 24,80 & 24,80 & 24,80 & 24,80 & 30,30 & 30,30 & 30,30 & 30,30 \\
\hline Caulim & 0,40 & 3,89 & 2,77 & 1,63 & 0,49 & 3,69 & 2,55 & 1,41 & 0,28 \\
\hline Fosfato Bicálcico & 1,90 & 1,31 & 1,31 & 1,31 & 1,31 & 0,83 & 0,83 & 0,83 & 0,83 \\
\hline Óleo Soja & 3,20 & 0,62 & 1,74 & 2,88 & 4,02 & 1,14 & 2,28 & 3,42 & 4,55 \\
\hline Calcário calcítico & 1,00 & 0,95 & 0,95 & 0,95 & 0,95 & 1,33 & 1,33 & 1,33 & 1,33 \\
\hline Sal comum & 0,49 & 0,45 & 0,45 & 0,45 & 0,45 & 0,45 & 0,45 & 0,45 & 0,45 \\
\hline L-lisina $\mathrm{HCl}-79 \%$ & 0,17 & 0,50 & 0,50 & 0,50 & 0,50 & 0,35 & 0,35 & 0,35 & 0,35 \\
\hline DL-metionina $-99 \%$ & 0,23 & 0,33 & 0,33 & 0,33 & 0,33 & 0,28 & 0,28 & 0,28 & 0,28 \\
\hline L-valina & - & 0,20 & 0,20 & 0,20 & 0,20 & 0,10 & 0,10 & 0,10 & 0,10 \\
\hline L-arginina & - & 0,16 & 0,16 & 0,16 & 0,16 & - & - & - & - \\
\hline L-treonina & - & 0,08 & 0,08 & 0,08 & 0,08 & - & - & - & - \\
\hline L-isoleucina & - & 0,08 & 0,08 & 0,08 & 0,08 & - & - & - & - \\
\hline Premix Mineral $^{2}$ & 0,10 & 0,10 & 0,10 & 0,10 & 0,10 & 0,10 & 0,10 & 0,10 & 0,10 \\
\hline Premix Vitamínico $^{3}$ & 0,10 & 0,10 & 0,10 & 0,10 & 0,10 & 0,10 & 0,10 & 0,10 & 0,10 \\
\hline Cloreto de colina $-60 \%$ & 0,05 & 0,05 & 0,05 & 0,05 & 0,05 & 0,05 & 0,05 & 0,05 & 0,05 \\
\hline Salinomicina $12 \%$ & 0,05 & 0,05 & 0,05 & 0,05 & 0,05 & 0,05 & 0,05 & 0,05 & 0,05 \\
\hline Bacitracina de $\mathrm{Zn}$ & 0,01 & 0,01 & 0,01 & 0,01 & 0,01 & 0,01 & 0,01 & 0,01 & 0,01 \\
\hline Fitase $^{4}$ & 0,00 & 0,02 & 0,02 & 0,02 & 0,02 & 0,02 & 0,02 & 0,02 & 0,02 \\
\hline \multicolumn{10}{|l|}{ Valores calculados } \\
\hline Proteína Bruta (\%) & 21,1 & 17,0 & 17,0 & 17,0 & 17,0 & 19,0 & 19,0 & 19,0 & 19,0 \\
\hline EMAn (kcal/kg) & 3000 & 2850 & 2950 & 3050 & 3150 & 2850 & 2950 & 3050 & 3150 \\
\hline Cálcio (\%) & 1,00 & 0,80 & 0,80 & 0,80 & 0,80 & 0,80 & 0,80 & 0,80 & 0,80 \\
\hline Fósforo disponível (\%) & 0,46 & 0,34 & 0,34 & 0,34 & 0,34 & 0,26 & 0,26 & 0,26 & 0,26 \\
\hline Lisina digestível (\%) & 1,15 & 1,15 & 1,15 & 1,15 & 1,15 & 1,16 & 1,16 & 1,16 & 1,16 \\
\hline Met+cist digestível (\%) & 0,81 & 0,82 & 0,82 & 0,82 & 0,82 & 0,81 & 0,81 & 0,81 & 0,81 \\
\hline Treonina digestível (\%) & 0,72 & 0,65 & 0,65 & 0,65 & 0,65 & 0,64 & 0,64 & 0,64 & 0,64 \\
\hline Isoleucina digestível (\%) & 0,83 & 0,72 & 0,72 & 0,72 & 0,72 & 0,74 & 0,74 & 0,74 & 0,74 \\
\hline Arginina digestível (\%) & 1,33 & 1,18 & 1,18 & 1,18 & 1,18 & 1,18 & 1,18 & 1,18 & 1,18 \\
\hline Valina digestível (\%) & 0,87 & 0,90 & 0,90 & 0,90 & 0,90 & 0,89 & 0,89 & 0,89 & 0,89 \\
\hline
\end{tabular}

PB - proteína bruta; Pd - fósforo disponível; EMAn - energia metabolizável aparente corrigida para nitrogênio

${ }^{1}$ Valores em $\mathrm{kcal} / \mathrm{kg}$ de matéria natural

${ }^{2}$ Fornecimento por kg de ração: $50 \mathrm{mg} \mathrm{Zn;} 20 \mathrm{mg} \mathrm{Fe;} 4 \mathrm{mg} \mathrm{Cu}$; 0,2 mg Co; 75 mg Mn; 1,5 mg I

${ }^{3}$ Fornecimento por kg de ração: 6 mg vit. B2; 12.000 UI vit. A; 2.200 UI vit D3; 53 mg nicotinamida; 2,2 mg vit.B1; 3,3 mg vit. B6;

16 mcg vit. B12; 0,11mg biotina; 1,0 mg ácido fólico; $130 \mathrm{mg}$ ácido pantotênico; 2,5 mg Vit. K3; 30 mg vit. E; 120 mg antioxidante

${ }^{4} 2500 \mathrm{FTU} / \mathrm{g}$ de ração 
Foram avaliados o consumo, o ganho de peso, a conversão alimentar e as excreções de nitrogênio, fósforo, cálcio, potássio, cobre e zinco pelas aves. Os dados foram submetidos à análise de variância utilizando-se primeiramente uma análise de variância global com todos os tratamentos para obter o quadrado médio do resíduo que foi utilizado para testar o fatorial e realizar o teste de Dunnet a 5\% para o controle. Para os tratamentos no esquema fatorial, utilizou-se o teste Student-Newman-Keuls (SNK) a 5\% de probabilidade. Todas as análises foram realizadas utilizando-se o programa estatístico Sisvar (FERREIRA, 2008).

\section{RESULTADOS E DISCUSSÃO}

Comparando-se a dieta controle com as demais, observou-se que os animais que receberam o menor nível protéico (17\%) e energético (2850 $\mathrm{kcal} / \mathrm{kg})$ apresentaram maior consumo $(\mathrm{P}<0,05)$, possivelmente para atender suas necessidades nutricionais (Tabela 2). Além disso, observou-se que o uso de fitase em dietas com níveis nutricionais reduzidos piorou o ganho de peso e a conversão alimentar $(\mathrm{P}<0,05)$.

Segundo PINCHASOV et al. (1990), diferentes taxas de absorção de aminoácidos e de peptídeos podem resultar em quantidades inadequadas de aminoácidos em locais específicos de síntese protéica celular, insuficiente para sustentar alta taxa de crescimento em especial de frangos na fase inicial. Neste caso, a diferença de digestão e de disponibilidade dos aminoácidos da proteína intacta, ou seja, a proteína do milho e do farelo de soja, em relação à disponibilidade dos aminoácidos cristalinos pode ter influenciado esses resultados.

BREGENDAHL et al. (2002) avaliaram rações com níveis reduzidos de proteína bruta para frangos na fase inicial e observaram que as aves que receberam rações com níveis reduzidos de proteína bruta (19 e 20\%) apresentaram desempenho inferior àquelas que consumiram ração com $23 \%$ desse nutriente. Por outro lado, ROSTAGNO et al. (2002) observaram que o nível de proteína da ração pode ser reduzido até $19 \%$, nesse caso, trabalhando com níveis normais de fósforo disponível e sem suplementação com enzimas.

Os resultados do presente trabalho se opõem aos obtidos por SILVA et al. (2006), que não observaram diferença no desempenho de frangos de corte de 1 a 21 dias de idade quando reduziram a proteína bruta até $17 \%$ e o fósforo disponível até $0,34 \%$, comparadas ao controle $(21 \%$ de proteína bruta e $0,45 \%$ de fósforo disponível). Isso demonstra a necessidade de mais estudos para determinar o nível adequado de nutrientes a ser utilizado em dietas para aves na fase inicial do desenvolvimento.

Considerando apenas as rações contendo fitase, não foram observadas interações $(\mathrm{P}>0,05)$ entre os níveis energéticos e nutricionais nas rações. A redução dos níveis de proteína bruta associada ao aumento do fósforo elevou $(\mathrm{P}<0,05)$ o consumo e o ganho de peso e reduziu $(\mathrm{P}<0,05)$ a conversão alimentar. Esses resultados sugerem que o uso de fitase deve estar associado à redução da proteína bruta ou que a quantidade de fósforo disponível em rações com $19 \%$ de proteína pode ter sido insuficiente, mostrando que, neste caso, a enzima não atuou de forma eficiente nesse nível do mineral estudado $(0,26 \%)$.

SILVA et al. (2006), trabalhando com os mesmos níveis de proteína e fósforo disponível em rações com fitase para frangos até 21 dias, não observaram diferenças ao reduzir esse mineral de 0,34 para $0,25 \%$ em rações com $19 \%$ de proteína bruta, mas observaram em rações com $17 \%$ de proteína bruta. Esses resultados sugerem que a redução do fósforo disponível é mais importante do que a da proteína, diminuindo o desempenho dos animais quando se reduz de forma excessiva a quantidade desse mineral na dieta.

Os níveis energéticos das rações não influenciaram $(\mathrm{P}>0,05)$ o ganho de peso das aves, porém reduziram $(\mathrm{P}<0,05)$ de forma linear $\mathrm{o}$ consumo $\left(Y=1958-0,2892 X ; R^{2}=0,99\right)$ e a conversão alimentar $\left(Y=2,651-0,0004 X ; R^{2}=\right.$ 0,98). De acordo com BARBOSA et al. (2008), as aves são capazes de regular o consumo em função dos níveis energéticos da dieta, mantendo o desempenho desde que a quantidade de nutrientes seja adequada.

Com relação à excreção de nutrientes pelas aves, comparando o controle às demais rações, foi possível observar que a inclusão de fitase combinada com diferentes níveis de energia, proteína e fósforo disponível influenciou $(\mathrm{P}<0,05)$ todos os parâmetros estudados (Tabela 3). Houve menor excreção de nitrogênio $(\mathrm{P}<0,05)$ em rações com o menor nível de proteína bruta estudado. Segundo BREGENDAHL et al. (2002), a redução de uma unidade percentual no teor de proteína da dieta pode diminuir a excreção de nitrogênio em 5 a $6 \%$. Uma redução de até $6,4 \%$ para cada unidade percentual de redução da proteína bruta na dieta foi observado no presente trabalho ao se comparar rações com $21 \%$ de proteína bruta (controle) com aquelas contendo 19\%, mantendo o nível energético. Nas demais dietas contendo 19\% de proteína bruta, o nível energético pode ter influenciado o adequado aproveitamento de aminoácidos.

De acordo com RAVINDRAN et al. 
(2000), o ácido fítico pode se complexar com enzimas como tripsina e pepsina, interferindo no balanço de nitrogênio por alterar a digestão de proteínas e absorção de aminoácidos. Nesse caso, ao se utilizar o conceito de proteína ideal, é preciso levar em consideração a quantidade de aminoácidos disponibilizados pela fitase. No presente trabalho, esta influência da fitase aparentemente não pode ser observada em rações contendo 19 ou $21 \%$ de proteína bruta e o mesmo nível energético.

A elevação dos níveis energéticos nas dietas resultou em aumento linear $(\mathrm{Y}=2387,07$ $\left.0,5789 X ; R^{2}=0,98\right)$ na excreção de nitrogênio pelas aves $(\mathrm{P}<0,05)$ apenas quando $17 \%$ de proteína bruta foi utilizado. Esse resultado pode estar relacionado ao menor teor desse nutriente associado ao efeito mais pronunciado da fitase na digestibilidade da proteína em menor nível e também ao menor consumo de ração pelas aves.

A inclusão de fitase nas rações também reduziu a excreção de fósforo pelas aves $(\mathrm{P}<0,05)$. Esses resultados, associados ao de desempenho, mostram que a redução do fósforo nas dietas com a inclusão da enzima é viável para diminuir o poder poluente das excretas. Amelhora na digestibilidade e no aproveitamento do fósforo, refletida pela menor excreção desse elemento, é esperada porque a fitase hidrolisa o complexo fitato-mineral, deixando o fósforo livre para absorção. No presente trabalho, a excreção absoluta de fósforo das aves que receberam rações com fitase e níveis reduzidos de $\mathrm{PB}$ foi aproximadamente 33,5\% inferior à daquelas que receberam a ração controle.

Tabela 2 - Desempenho de frangos de 1 aos 21 dias recebendo rações com diferentes níveis de proteína bruta e fósforo disponível e energia metabolizável aparente corrigida

\begin{tabular}{|c|c|c|c|c|c|}
\hline \multirow{2}{*}{ Ração } & \multicolumn{4}{|c|}{ EMAn (kcal/kg) } & \multirow{2}{*}{ Média } \\
\hline & 2850 & 2950 & 3050 & 3150 & \\
\hline \multicolumn{6}{|c|}{ Consumo de ração (g/ave) } \\
\hline $17 \%$ PB e $0,34 \%$ Pd & $1153 *$ & 1119 & 1085 & 1056 & $1103 a$ \\
\hline $19 \% \mathrm{~PB}$ e $0,26 \% \mathrm{Pd}$ & 1120 & 1085 & 1067 & 1041 & $1078 b$ \\
\hline Média $^{1}$ & 1136 & 1102 & 1076 & 1049 & 1091 \\
\hline Controle $^{2}$ & 1085 & & & & \\
\hline $\mathrm{CV}(\%)$ & 3,42 & & & & \\
\hline \multicolumn{6}{|c|}{ Ganho de peso (g/ave) } \\
\hline $17 \%$ PB e $0,34 \%$ Pd & $760 *$ & $755^{*}$ & $757 *$ & $750 *$ & $755 \mathrm{a}$ \\
\hline $19 \%$ PB e $0,26 \%$ Pd & $718^{*}$ & $723^{*}$ & $738 *$ & $723 *$ & $726 b$ \\
\hline Média & 739 & 739 & 748 & 736 & 741 \\
\hline Controle & 802 & & & & \\
\hline $\mathrm{CV}(\%)$ & 3,41 & & & & \\
\hline \multicolumn{6}{|c|}{ Conversão alimentar } \\
\hline $17 \% \mathrm{~PB}$ e $0,34 \% \mathrm{Pd}$ & $1,52^{*}$ & $1,48^{*}$ & $1,43^{*}$ & 1,41 & $1,46 \mathrm{a}$ \\
\hline $19 \% \mathrm{~PB}$ e $0,26 \% \mathrm{Pd}$ & $1,56^{*}$ & $1,50^{*}$ & $1,45^{*}$ & $1,44^{*}$ & $1,49 b$ \\
\hline Média $^{1}$ & 1,54 & 1,49 & 1,44 & 1,42 & 1,47 \\
\hline Controle & 1,35 & & & & \\
\hline $\mathrm{CV}(\%)$ & 2,82 & & & & \\
\hline
\end{tabular}

PB - proteína bruta; Pd - fósforo disponível; EMAn - energia metabolizável aparente corrigida para nitrogênio

* Médias diferem do tratamento controle pelo teste de Dunnet $(\mathrm{P}<0,05)$

${ }^{1}$ Médias seguidas por diferentes letras na mesma coluna diferem pelo teste de $\mathrm{F}(\mathrm{P}<0,05)$

${ }^{2}$ Dieta controle contendo $21 \%$ de proteína bruta e $3000 \mathrm{kcal} / \mathrm{kg}$ de EMAn e $0,46 \%$ de Pd 
Tabela 3 - Excreção de nutrientes (mg/ave/dia) por frangos de corte de 1 aos 21 dias recebendo rações com diferentes níveis de proteína bruta e fósforo disponível e energia metabolizável aparente corrigida

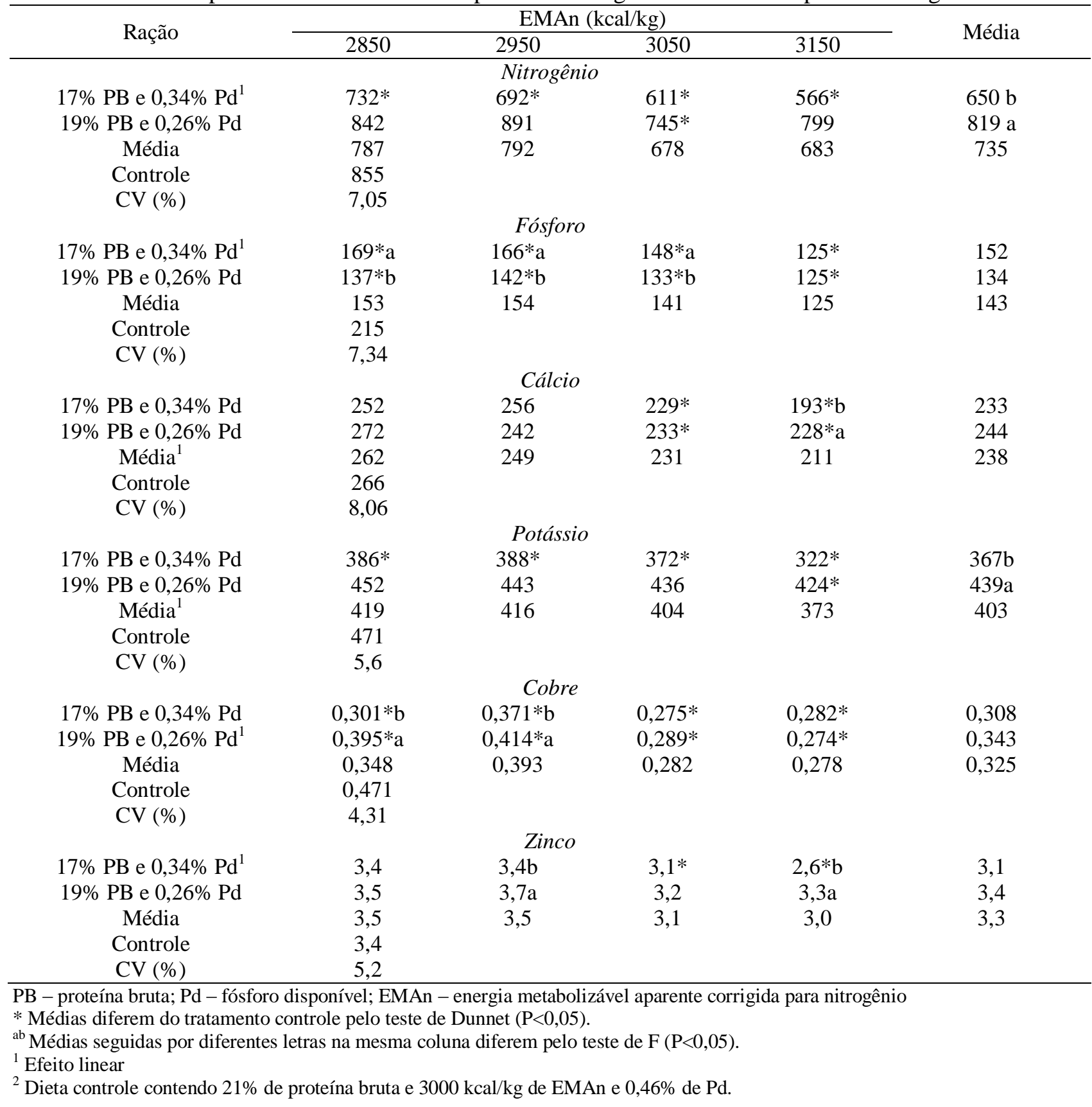

Comparando-se rações com fitase, observouse que a redução do fósforo em rações com $19 \%$ de proteína diminuiu a excreção desse elemento, exceto quando o maior nível de energia foi utilizado, provavelmente devido ao menor consumo de ração nesse nível energético. Esses resultados confirmam os obtidos por SILVA et al. (2008), que também observaram redução na excreção de fósforo em rações com $0,26 \%$ desse elemento em relação ao nível de $0,34 \%$.

O aumento dos níveis energéticos das rações reduziu de forma linear $\left(y=-0,15 x+602 ; R^{2}=0,92\right)$ a excreção do fósforo $(\mathrm{P}<0,05)$ somente em rações contendo $0,34 \%$ desse elemento. Esse resultado pode estar relacionado ao menor consumo observado com o aumento dos níveis energéticos das rações. No entanto, o mesmo efeito linear não pode ser observado em rações com $0,26 \%$ de fósforo disponível, ou seja, nesse nível de fósforo a redução do consumo pela ave com o aumento dos níveis energéticos da ração não afetou a quantidade do elemento excretado, sugerindo que as aves são capazes de reter mais fósforo quando o mesmo encontra-se limitado na dieta. A partir desse resultado, sugere-se que a quantidade de fósforo normalmente utilizada em rações pode estar superestimada, uma vez que as aves podem se 
adaptar em condições de menor disponibilidade do mineral.

Quanto ao cálcio, foram observadas $(\mathrm{P}<0,05)$ redução de sua eliminação com a inclusão de fitase apenas quando se utilizaram os maiores níveis energéticos em relação ao controle. Considerando rações com fitase, a redução da proteína associada ao maior nível de fósforo reduziu a excreção apenas em rações com $3150 \mathrm{kcal} \mathrm{EM} / \mathrm{kg}$, provavelmente em função do menor consumo de ração associada à melhor relação cálcio:fósforo.

De acordo com VIVEIROS et al. (2002), o uso de fitase reduz a excreção de cálcio e fósforo no ambiente, provavelmente por disponibilizar maior quantidade desses elementos. Isso permite reduzir suas quantidades nas rações, levando, consequentemente, a uma menor quantidade excretada. SILVA et al. (2008) também observaram redução na excreção de cálcio ao trabalharem com rações com $3000 \mathrm{kcal} \mathrm{EM} / \mathrm{kg}$ contendo fitase, independente dos níveis de proteína bruta. Neste mesmo trabalho, o consumo pelas aves não diferiu entre as dietas, sugerindo maior disponibilidade desse mineral.

Com relação à excreção de potássio, observou-se redução $(\mathrm{P}<0,05)$ na excreção em todas as rações contendo proteína bruta reduzida. Nessas rações, a quantidade de farelo de soja é menor, contribuindo para a menor ingestão do elemento e, consequentemente, menor excreção e maior aproveitamento pelas aves. Da mesma forma que a excreção de cálcio, a inclusão de energia reduziu $(\mathrm{P}<0,05)$ de forma linear a excreção de potássio pelas aves.

A inclusão de fitase também reduziu $(\mathrm{P}<0,05)$ a excreção de cobre, quando comparadas ao controle. Já em rações contendo a enzima, a redução da proteína bruta foi eficiente em reduzir a excreção do elemento somente quando o menor nível energético foi utilizado $(2850 \mathrm{kcal} / \mathrm{kg})$. Esse resultado pode estar relacionado ao maior consumo observado nesse nível energético em relação aos demais. Nesse caso, a quantidade de nutrientes consumidos foi maior e o efeito da redução da proteína bruta com inclusão de aminoácidos torna-se mais pronunciado. Isso se deve à menor complexação deste às proteínas da dieta, favorecendo a absorção e a retenção pelos animais.

Quanto ao zinco, a inclusão de fitase reduziu $(\mathrm{P}<0,05)$ sua excreção apenas em rações com o nível mais baixo de proteína bruta $(17 \%)$ e com os níveis mais altos de energia (3050 e $3150 \mathrm{kcal} / \mathrm{kg}$ de EMAn). Além disso, observou-se que os níveis energéticos reduziram de forma linear $(\mathrm{P}<0,05)$ a excreção desse elemento apenas em rações com $17 \%$ de proteína bruta. VIVEIROS et al. (2002) verificaram que o uso de fitase foi capaz de aumentar a retenção de zinco pelas aves, o que sugere que o mineral esteja também complexado à molécula de fitato. No presente estudo, pode-se observar menor excreção de zinco apenas em rações com níveis energéticos mais elevados. Isso pode estar relacionado ao menor consumo pelas aves nesses níveis de energia utilizado. Nesse caso, a fitase não foi eficaz na liberação do mineral em sua forma complexada. Por outro lado, a eficiência de retenção de zinco também pode estar relacionada aos níveis de cobre na dieta e à genética utilizada.

Com base nesses resultados, a manipulação dos níveis nutricionais de dietas contendo fitase pode contribuir de forma significativa na redução de elementos poluentes nos dejetos, porém o desempenho pode ser comprometido. Os resultados do presente trabalho sugerem que mais estudos devem ser conduzidos ao se considerar diferentes planos nutricionais em rações com fitase, principalmente utilizando-se o conceito de proteína ideal na formulação de rações para frangos de corte.

\section{CONCLUSÃO}

O uso de fitase em rações com níveis reduzidos de proteína bruta e fósforo disponível é eficaz em reduzir a emissão de elementos poluentes nas excretas de frangos de corte até a terceira semana de vida; contudo, ele reduz o ganho de peso das aves e aumenta a conversão alimentar.

\section{AGRADECIMENTOS}

Os autores agradecem ao $\mathrm{CNPq}$ pelo financiamento do projeto e à Fapemig pelo apoio.

\section{REFERÊNCIAS}

BARBOSA, F.J.V.; LOPES, J.B.; FIGUEIRÊDO, A.V.; ABREU, M.L.T.; DOURADO, L.R.B.; FARIAS, L.A.F.; PIRES, J.E.P. Níveis de energia metabolizável em rações para frangos de corte mantidos em ambiente de alta temperatura. Revista Brasileira de Zootecnia, v.37, n.5, p.849-855, 2008.

BREGENDAHL, K., SELL, J.L.; ZIMMERMAN, D.R. Effect of low-protein diets on growth performance and body composition of broiler chicks. Poultry Science, v.81, p.1156-1167, 2002.

CONTE, A.J.; TEIXEIRA, A.S.; FIGUEIRÊDO, A.V.; VITTI, D.M.S.S.; SILVA FILHO, J.C. Efeito da fitase na biodisponibilidade do fósforo do farelo de arroz em frangos de corte. Pesquisa Agropecuária 
Brasileira, v. 37, n. 4, p. 547-552, 2002.

FERREIRA, D.F. SISVAR: um programa para análises e ensino de estatística. Revista Científica Symposium, v. 6, n. 2, p. 36-41, 2008.

MATTERSON, L.D.; POTTER, L.M.; STUTZ, M.W. The metabolizable energy of feed ingredients for chickens. Storss, Connecticut: The University of Connecticut, Agricultural Experiment Station, 1965. 11 p. (Research Report, 7).

PINCHASOV, Y.; MENDONCA, C.X.; JENSEN, L.S. Broiler chick response to low protein diets supplemented with synthetic amino acids. Poultry Science, v. 69, n. 11, p. 1950-1955, 1990.

RAVINDRAN, V.; CABAHUG, S.; RAVINDRAN, G.; SELLE, P.H.; BRYDEN, W.L. Response of broiler chickens to microbial phytase supplementation as influenced by dietary phytic acid and non-phytate phosphorous levels. II. Effects on apparent metabolisable energy, nutrient digestibility and nutrient retention. British Poultry Science, v. 41, n. 2, p. 193-200, 2000.

RODRIGUES, P.B.; MARTINEZ, R.S.; FREITAS, R.T.F.; BERTECHINI, A.G.; FIALHO, E.T. Influência do tempo de coleta e metodologias sobre a digestibilidade e o valor energético de rações para aves. Revista Brasileira de Zootecnia, v. 34, p. 882-889. 2005.

ROSTAGNO, H.S.; ALBINO, L.F.T.; DONZELE, J.L.; GOMES, P.C.; OLIVEIRA, R.F.; LOPES, D.C.; FERREIRA, A.S.; BARR, S.L.T. Tabelas brasileiras para aves e suínos. Composição de alimentos e exigências nutricionais. Viçosa: UFV, 2000. 141p.

ROSTAGNO, H.S.; VARGAS JÚNIOR, J.G.; ALBINO, L.F.T.; TOLEDO, R.S.; OLIVEIRA, J.E.; CARVALHO, D.C.O. Níveis de proteína e aminoácidos em rações de pinto de corte. Revista Brasileira de Ciência Avícola, v. 4, p. 49, 2002. (Suplemento).

SCHOULTEN, N.A.; TEIXEIRA, A.S.; BERTECHINI, A.G.; FREITAS, R.T.F.; CONTE, A.J.; SILVA, H.O. Efeito dos níveis de cálcio sobre a absorção de minerais em dietas iniciais para frangos de corte suplementadas com fitase. Ciência e Agrotecnologia, v.26, p.1313-1321, 2002.

SCHOULTEN, N.A.; TEIXEIRA, A.S.; FREITAS, R.T.F.; BERTECHINI, A.G.; CONTE, A.J.; SILVA, H.O. Níveis de cálcio em rações de frangos de corte na fase inicial suplementadas com fitase. Revista Brasileira de Zootecnia, v.32, p.1190 - 1197, 2003.

SILVA, D.J.; QUEIROZ, A.C. Análise de alimentos: métodos químicos e biológicos. 3. ed. Viçosa: UFV. Imprensa Universitária, 2002. 235p.

SILVA, Y.L.; RODRIGUES, P.B.; FREITAS, R.T.F.; BERTECHINI, A.G.; FIALHO, E.T.; FASSANI, E.J.; PEREIRA, C.R. Redução de proteína e fósforo em rações com fitase para frangos de corte, no período de 1 a 21 dias de idade. Desempenho e teores de minerais na cama. Revista Brasileira de Zootecnia, v. 35, n. 3, p. 833-841, 2006.

SILVA, Y.L.; RODRIGUES, P.B.; FREITAS, R.T.F.; ZANGERONIMO, M.G.; FIALHO, E.T. Níveis de proteína e fósforo em rações com fitase para frangos de corte, na fase de 14 a 21 dias de idade.Valores energéticos e digestibilidade de nutrientes. Revista Brasileira de Zootecnia, v.37, n.3, p.469-477, 2008.

VIVEIROS, A.; BRENES, A.; ARIJA, I.; CENTENO, C. Effects of microbial phytase supplementation on mineral utilization and serum enzyme activities in broiler chicks fed different levels of phosphorus. Poultry Science, v. 81, n. 8, p. 1172-1183, 2002.

Protocolado em: 24 jun. 2010 Aceito em 14 set. 2011. 